\title{
PERBEDAAN KUANTITAS TIDUR SEBELUM DAN SESUDAH PIJAT BAYI
}

\author{
Maria A.D Barbara ${ }^{1}$, Sarah S. Rahayu ${ }^{2}$ \\ ${ }^{1,2)}$ Program Studi Sarjana Kebidanan Institut Kesehatan Rajawali \\ mariaawaldina1992@gmail.com
}

\begin{abstract}
ABSTRAK
Masalah tidur pada bayi di Indonesia umumnya berkisar 44\%. Masalah tidur dapat mengganggu pertumbuhan, menurunkan imunitas dan mengganggu sistem endokrin. Salah satu cara agar bayi tidur nyenyak ialah dengan melakukan pijatan. Karena pijatan membuat tidur lebih lelap dan mengurangi masalah tidur. Untuk mengetahui perbedaan kuantitas tidur bayi usia 6-12 bulan sebelum dan sesudah dilakukan pijat bayi di Wilayah Desa Cihanjuang Rahayu Kecamatan Parongpong tahun 2019. Penelitian ini menggunakan metode Quasi-experiment dengan rancangan one group pre and post test design. Sampel yang digunakan yaitu seluruh bayi di Desa Cihanjuang Rahayu Kecamatan Parongpong berjumlah 29 responden. Pengumpulan data menggunakan lembar angket. Analisis data yaitu univariat bivariat untuk melihat distribusi dan perbedaan kuantitas tidur bayi sebelum dan sesudah dilakukan pijatan. Kuantitas tidur bayi rata-rata sebelum adanya pemijatan sekitar 13,59 jam/hari dan setelah dilakukan pemijatan meningkat menjadi $14,88 \mathrm{jam} /$ hari. Hasil uji statistik terdapat perbedaan antara kuantitas tidur bayi sebelum dan sesudah adanya pemijatan dengan nilai $p$-value $0,000<\mathrm{a}=0,05$ yang dapat diartikan adanya perbedaan yang bermakna antara bayi sebelum dilakukan pemijatan dan setelah pemijatan. Terdapat perbedaan antara kuantitas tidur bayi sebelum dan sesudah dilakukan pijatan.
\end{abstract}

Kata kunci : kuantitas tidur, masalah tidur, pijat bayi

\section{Abstract}

Babies problems sleep in Indonesia are around 44\%. Sleep problems can interfere with growth, decrease immunity and interfere with the endocrine system. One way for babies sleep soundly is by doing massage, because massage makes sleep more soundly and make sleep problems less. Determine the differences in the quantity of infant sleep aged 6-12 months before and after baby massage in the village of Cihanjuang Rahayu, Parongpong Sub-District in 2019. This research uses Quasi-experiment design with one group pre and post-test design. The sample used all babies in Cihanjuang Rahayu Village Parongpong Sub-district. The sample used a total sampling of 29 respondents. Techniques of this research using questionnaire sheets. Analysis of this research is univariate and bivariate, to see the frequency of distribution and the differences quantity of infant sleep before and after the massage. Quantity average of infant sleep before the massage was 13,59 hours/ day and after massage increased to 14,88 hours/day. Statistical test results obtained there are differences between the quantity of baby sleep before and after massage with a value of $p$-value 0,000<a=0,05 which means that there is a significant difference between the quantity of baby sleep before and after the massage. In this research there were differences in the quantity of baby sleep before and after the massage

Keywords: baby massage, problems sleep, quantity of baby's sleep 


\section{PENDAHULUAN}

Kebutuhan bayi untuk tidur, bangun dan menangis berbeda antara tiap bayi. Selama fase bayi, pertumbuhan sel-sel syaraf belum sempurna sehingga diperlukan waktu tidur yang lebih lama untuk perkembangan syaraf sehingga untuk tubuh yang maksimal bayi membutuhkan waktu yang cukup. (Sulistyorini \& Cahyaningrum, 2013). Bentuk adaptasi bayi dengan lingkungan adalah dengan tidur. Seusai lahir, bayi umumnya tidur selama 16-20 jam dalam sehari. Bayi lebih banyak tidur malam dibandingkan siang hari pada usia 2 bulan. Pada umur 3-6 bulan, jumlah tidur siang semakin berkurang, kira-kira 3 kali dan terus berkurang. Bayi berumur 6-12 bulan umumnya hanya tidur siang dua kali. Saat berumur 1 tahun, bayi umumnya hanya akan tidur siang satu kali dan sisanya di waktu malam hari. Keseluruhan jumlah waktu tidur bayi berada di kisaran 12-14 jam/hari (Prasadja, 2009).

Sebuah hasil penelitian menyebutkan bahwa sentuhan dapat membuat sesuatu yang positif untuk bayi. Sentuhan dapat membuat bayi tenang serta nyaman. Adanya pemijatan yang sesuai, akan membuat tidur bayi lebih efektif dan meningkatkan nafsu makannya (Subakti, 2008).

Di Indonesia, penelitian yang dilakukan di Bandung, Jakarta, Palembang, Medan dan Batam dan melibatkan 385 orang didapat 51,3\% bayi mempunyai gangguan pada tidur, $42 \%$ bayi tidur malamnya kurang dari 9 jam. Bayi akan terbangun lebih dari tiga kali dan lama bangunnya lebih dari 1 jam pada malam hari. Cara pengobatan tertua di dunia adalah pijat. Pijat yaitu seni dalam merawat kesehatan dan pengobatan yang bertujuan untuk membuat persendian yang kaku menjadi lemas. Pijat bukan hanya dilakukan di salon dan spa tapi juga di fasilitas kesehatan. Sekarang terapi pijat telah banyak berguna untuk meningkatkan berat badan bayi dan meningkatkan kesehatan (Syaukani, 2015).
Pemerintah menaruh perhatian pada bayi melalui campur tangan Bidan. Standar Profesi Bidan menyebutkan bahwa kewenangan dalam melakukan pemantauan serta stimulasi tumbang bayi serta anak dapat dilakukan oleh bidan. Penerapan stimulasi yang dilakukan bidan adalah terapi pijat pada bayi, dan diharapkan masyarakat bisa menerapkan terapi tersebut sesuai petunjuk dari Bidan. Berdasarkan studi pendahuluan yang dilakukan di Desa Cihanjuang Rahayu melalui wawancara yang dilakukan peneliti kepada 10 orang ibu yang mempunyai bayi berusia 6-12 bulan, rata-rata keluhan yang dialami ibu yaitu seperti bayi biasa bangun di malam hari dan durasi terbangun lebih dari 60 menit, bayi yang tidak terpenuhi tidurnya pada malam hari keesokan harinya akan rewel, menangis serta sulit diberhentikan yang berakibat pada kurangnya kecukupan tidur bayi. Berdasarkan informasi bersama kader didapat bahwa pijat bayi belum terlaksana secara rutin bahkan jarang sekali dilakukan baik dalam kegiatan pelayanan KIA maupun dilakukan oleh ibu kepada bayinya namun salah satu dari ibu bayi pernah memijatkan bayinya kepada paraji pada saat sakit atau cedera dan setelah di pijat selain berfungsi untuk meringankan cedera yang dialami bayi ternyata tidurnya pun menjadi lebih lelap dan lama.

Berdasarkan uraian di atas, maka peneliti merasa tertarik untuk melakukan penelitian dengan judul "Perbedaan Kuantitas Tidur Bayi Usia 6-12 Bulan Sebelum Dan Sesudah Dilakukan Pijat Bayi Di Wilayah Desa Cihanjuang Rahayu Kecamatan Parongpong Tahun 2019”.

\section{METODOLOGI}

Metode penelitian yang digunakan yaitu Quasi Experimental (eksperimen semu). Cara ini diartikan untuk mencari adanya pengaruh perlakuan pada sesuatu dalam keadaan yang dapat dikendalikan. Rancangan penelitian ini dengan One Group Pre and Post-Test Design. 
Untuk cara ini akan ada prates sebelum adanya perlakuan sehingga hasilnya diketahui lebih terpercaya karena adanya perbandingan dengan kondisi sebelumnya (Sugiyono, 2016).

Sampel yang digunakan dalam penelitian ini dengan menggunakan teknik pengambilan sampel total sampling dengan jumlah responden 29 orang dan menggunakan analisis uji statistik Wilcoxon Signed Rank Test.

Jenis data yang digunakan dalam penelitian ini menggunakan data primer dan sekunder. Instrumen yang digunakan dalam penelitian ini yaitu menggunakan lembar angket yang diisi oleh ibu bayi untuk mengetahui informasi lama tidur bayi.

HASIL

\section{Analisis Univariat}

Tabel 1. Distribusi Frekuensi Kuantitas

Tidur Bayi 6-12 Bulan Sebelum Pijat Bayi di Wilayah Cihanjuang Rahayu Tahun 2019

\begin{tabular}{ccc} 
& $(\mathbf{n}=\mathbf{2 9})$ \\
\hline & Mean & Std. Deviasi \\
\hline $\begin{array}{c}\text { Sebelum } \\
\text { dilakukan pijat } \\
\text { bayi }\end{array}$ & $\begin{array}{c}\text { 13,59 } \\
\text { jam/hari }\end{array}$ & 825 \\
\hline
\end{tabular}

(Sumber : Data Primer, 2019)

Hasil penelitian menunjukkan bahwa bayi sebelum dilakukan pemijatan di dapat kuantitas tidur rata-rata $13,59 \mathrm{jam} / \mathrm{hari}$.

Tabel 2. Distribusi Frekuensi Kuantitas Tidur Bayi 6-12 Bulan Sesudah n Pijat Bayi di Wilayah Desa Cihanjuang Rahayu Tahun $2019(n=29)$

\begin{tabular}{ccc}
\hline & Mean & Std. Deviasi \\
\hline $\begin{array}{c}\text { Sesudah } \\
\text { dilakukan pijat } \\
\text { bayi }\end{array}$ & $\begin{array}{c}14,88 \\
\text { jam/hari }\end{array}$ & 997 \\
\hline
\end{tabular}

(Sumber : Data Primer, 2019)

Hasil penelitian didapat bayi sesudah dilakukan pijat, kuantitas tidurnya menjadi 14,88 jam/hari.

\section{Analisis Multivariat}

Tabel 3. Perbedaan Kuantitas Tidur Bayi 6-12 Bulan Sebelum dan Sesudah Pijat Bayi di Wilayah Cihanjuang Rahayu Tahun 2019

\begin{tabular}{ccc} 
& $(\mathbf{n = 2 9 )}$ & \\
\hline & $\mathbf{Z}$ & $\mathbf{P}$ \\
\hline $\begin{array}{c}\text { Sesudah } \\
\text { dilakukan pijat } \\
\text { bayi }\end{array}$ & -4.496 & $-0,000$ \\
\hline
\end{tabular}

(Sumber : Data Primer, 2019)

Hasil penelitian perbedaan kuantitas tidur bayi sebelum dan sesudah dilakukan pemijatan didapat $p$ value $0,000<0,05$.

\section{PEMBAHASAN}

1. Kuantitas Tidur Bayi 6-12 Bulan Sebelum Pijat Bayi Di Wilayah Cihanjuang Rahayu Tahun 2019

Penelitian yang dilakukan pada bulan Juni sampai dengan Juli 2019 yang dilakukan pada 29 responden, akumulasi tidur pada bayi sebelum dilakukan pijat sekitar 13,59 jam/hari.

Menurut teori, bayi usia 6-12 bulan merupakan tahap perkembangan mulai belajar merangkak, duduk dan berjalan. Sekitar umur 1 tahun umumnya bayi tidur siang satu kali dan sisanya di malam hari. Jumlah tidur bayi sekitar 12-14 jam/hari. Dalam hal ini tidur bayi adalah normal tetapi selain dari sisi kuantitasnya, dilihat juga dari sisi kualitas tidur bayi tersebut, bayi yang sering rewel di malam hari dengan durasi terbangun lebih dari 1 jam sudah termasuk ke dalam gangguan tidur. (Prasadja, 2009)

Menurut asumsi peneliti dari hasil analisis, rata-rata kuantitas tidur bayi disini adalah normal yaitu 13,59 jam/hari. Hal ini sesuai dengan teori yang menyatakan bahwa bayi berumur 6-12 bulan tidur siang hari hanya dalam 2 kali. Hal ini disebabkan bayi mulai terpengaruh lingkungan dan akan 
bangun bila marah dan lelah. Menjelang umur 1 tahun ia hanya satu kali tidur siang dan sisanya di malam hari dan didapat akumulasi tidur bayi berada pada kisaran 12$14 \mathrm{jam} / \mathrm{hari}$.

2. Kuantitas Tidur Bayi Usia 6-12 Bulan Sesudah Dilakukan Pijat Bayi di Wilayah Desa Cihanjuang Rahayu Kecamatan Parongpong Tahun 2019

Sesudah dilakukan pijat bayi selama 2 kali dalam 1 minggu dalam jangka waktu 4 minggu, kuantitas tidur bayi mengalami peningkatan menjadi 14,88 jam/hari dan rata-rata penambahan waktu 1,29 jam/hari.

Hal ini sesuai dengan teori yang menyatakan bahwa otot-otot bayi yang dilakukan stimulasi dengan urut akan membuat bayi merasa nyaman serta mengantuk. Umumnya bayi setelah dipijat akan langsung tidur dengan durasi yang lama. Ini menandakan kalau bayi tenang dan terapi sentuhan yang dilakukan tersebut dapat memberi efek yang baik pada bayi (Subakti, 2008).

Pijat adalah terapi tertua di dunia. Pijat adalah stimulasi yang dapat menjadikan tubuh orang yang dipijat menjadi hangat. Sejak manusia dilahirkan pun, ia sudah mendapatkan sentuhan kasih dari ibu atau ayahnya. Itulah sebabnya, sentuhan yang diberikan melalui pemijatan dapat mampu mempererat hubungan antara si pemijat dengan anak atau orang yang dipijat. (Suranto, 2011)

Dalam penelitian setelah adanya terapi pijat pada responden didapat terjadi peningkatan dalam jumlah tidur. Hal ini berarti pijat memberi efek positifyakni terjadi peningkatan jumlah tidur pada bayi. Tetapi 3 responden $(6,89 \%)$ dalam penelitian ini tidak terjadi peningkatan dalam jumlah tidur. Ini disebabkan bayi sedang dalam kondisi sakit saat perlakuan sehingga berdampak pada jumlah tidurnya.

Ada beberapa hal yang berperan dalam kuantitas tidur yang dialami bayi yaitu internal dan eksternal. Eksternal yang berperan dalam hal ini yaitu lingkungan. Suasana yang tidak tenang berdampak pada jumlah tidur bayi, tempat tidur bayi yang telah diatur sedemikian rupa dan juga posisi saat terlelap. Unsur internal yang berperan yaitu keadaan kesehatan bayi. Di minggu terakhir dalam bulan, ada 3 bayi yang flu dan batuk ringan namun tetap dilakukan terapi pijat dengan pertimbangan bayi tetap dapat dilakukan pijat.

Penelitian ini sesuai dengan penelitian sebelumnya yaitu"Pengaruh Pijat Bayi Terhadap Tingkat Pemenuhan Tidur Bayi Usia 3-6 Bulan Di Wilayah Kerja Puskesmas Umbulharjo I Yogyakarta" hasil penelitian yaitu terdapat peningkatan kuantitas tidur bayi sesudah dilakukan pemijatan yaitu ratarata $15,83 \mathrm{jam} /$ hari sedangkan pada saat sebelum dilakukan pemijatan rata-rata lama tidurnya hanya $11,1 \mathrm{jam} /$ hari dengan rerata peningkatannya sebanyak 3,73 jam/hari (Kustiningsih, 2016).

Menurut asumsi peneliti kuantitas tidur sebelum dan setelah dilakukan pijat bayi dalam batas batas normal meskipun ada perbedaan. Kebutuhan tidur pada bayi akan berbeda berdasarkan usia. Tetapi jika bayi tidur melebihi batas normal namun masih berada di atas rata-rata dengan jumlah tidur bayi lainnya tidak perlu khawatir cukup dengan membangunkannya pada saat jadwal waktu menyusu.

3. Perbedaan Kuantitas Tidur Bayi 6-12 Bulan Sebelum dan Sesudah Pijat Bayi di Wilayah Cihanjuang Rahayu Tahun 2019

Dari uji Wilcoxon Signed Rank Test diperoleh hasil bahwa secara keseluruhan 
terdapat perbedaan yang bermakna antara kuantitas tidur bayi 6-12 bulan sebelum dan sesudah dilakukan pijat bayi dengan besarnya nilai $Z$ yaitu $-4,496$ dengan $p=$ value sebesar 0,000 dimana nilai $0,000 a<0,05$. Hasil uji wilcoxon menyatakan bayi yang sudah diberikan pemijatan mengalami peningkatan kuantitas tidur dibandingkan pada saat belum dilakukan pemijatan.

Hal ini sesuai dengan dengan teori yang menunjukkan bahwa bayi yang diberikan pijat, maka akan meningkatkan tonus otot berupa nervus vagus. Peningkatan kerja tonus otot meningkatkan pula produksi gastrin serta insulin yang menyebabkan penyerapan makanan lebih berjalan baik. Pemijatan pada bayi juga akan meningkatkan daya tahan tubuh karena aktivitas neuro transmitter neurontin akan meningkat sehingga kapasitas sel reseptor yang memiliki fungsi mengikat glucocorticoid meningkat. (Juwita, 2019).

Berdasarkan pernyataan dari beberapa keuntungan yang didapat bayi bila kebutuhan akan tidurnya cukup yaitu lebih tenang, bangun di pagi hari dengan bugar, serta mempunyai gairah dalam melakukan kegiatan-kegiatan ringan lain. Tidur memiliki manfaat untuk kesehatan mental, emosi serta fisik dan daya tahan tubuh. Kecukupan tidur akan membuat perbaikan pada sel otak bayi serta memproduksi hormone pertumbuhan. Oleh sebab itu kecukupan tidur pada bayi harus terpenuhi agar perkembangannya dapat berjalan dengan baik. (Prasetyo, 2009)

Hasil penelitian ini juga didukung oleh penelitian dengan judul "Hubungan Frekuensi Pijat Bayi Dengan Kualitas Tidur Bayi Usia 6-12 Bulan di Asri Medical Center Yogyakarta " kepada 52 orang bayi, menunjukkan hasil perhitungan uji statistik menggunakan uji chi-square diperoleh nilai $\mathrm{p} \quad 0.003<0,005$, menunjukkan bahwa terdapat hubungan frekuensi pijat bayi dan kualitas tidur. Dari data hasil riset frekuensi pijat bayi terdapat 24 responden (46,2\%) dengan frekuensi kurang dan 28 responden $(53,8 \%)$ dengan frekuensi baik. Sedangkan kualitas tidur bayi didapatkan 9 responden $(17,3 \%)$ bayi yang tidurnya kurang, 17 responden $(32,7 \%)$ kualitas tidur sedang dan 26 responden (50\%) kualitas tidur baik (Haniyyah, 2013)

Menurut asumsi peneliti akan ada perbedaan kuantitas tidur bayi sebelum dan sesudah pijat dikarenakan saat diberikan pemijatan tubuh bayi menjadi rileks dan nyaman yang disebabkan oleh pengeluaran hormon endorphin dan hormon serotonin yang akan mempengaruhi lama tidur bayi.

\section{SIMPULAN DAN SARAN}

Berdasarkan hasil penelitian dan pembahasan maka peneliti menyimpulkan bahwa rerata kuantitas tidur bayi sebelum adanya pijat sekitar13,59 jam/hari, adanya peningkatan kuantitas tidur bayi sesudah pijat menjadi 14,88 jam/hari dengan selisih 1,29 jam/ hari dan berdasarkan analisis uji statistik Wilcoxon Sign Rank Test terdapat perbedaan yang bermakna antara kuantitas tidur bayi sebelum dan sesudah dilakukan pijat bayi.

Disarankan ibu harus tetap menerapkan pijat bayi dalam kehidupan sehari-hari secara rutin guna untuk meningkatkan stimulasi pada bayi dan mencegah gangguan-gangguan kesehatan pada bayi serta menyebarluaskan informasi mengenai pijat bayi yang sangat penting bagi bayi.

Disarankan bidan untuk terus memberikan sosialisasi teknik pijat bayi kepada orang tua bayi dengan metode yang sesuai dengan kondisi dan keadaan orang tua baik melalui leaflet maupun video sebagai salah satu upaya meningkatkan 
kesehatan dan bounding attachment antara ibu dan bayi yang akan mempengaruhi pada kuantitas tidur bayi.

Disarankan untuk penelitian selanjutnya dapat memperbanyak jumlah responden, menambah variabel, memakai desain penelitian dua kelompok atau yang lebih variatif serta dapat mengadakan pelatihan mengenai pijat bayi yang lebih intensif pada ibu bayi.

\section{DAFTAR PUSTAKA}

Haniyyah. (2013). Hubungan Frekuensi Pijat Bayi Dengan Kualitas Tidur Bayi Usia 6-12 Bulan Di Asri Medical Center Yogyakarta. 1-11.

Juwita, S. \& N. D. J. (2019). Pijat Bayi (A. D. Alristina (ed.); I). CV.Sarnu Untung.

Kustiningsih, L. L. U. (2016). Pengaruh Pijat Bayi Terhadap Tingkat Pemenuhan Kebutuhan Tidur Bayi Usia 3-6 Bulan Di Wilayah Kerja Puskesmas Umbulharjo I Yogyakarta Tahun 2016. http://digilib.unisayogya.ac.id/2013/1/
Naskah Publikasi Listina Laili Ulfah $\% 28201510104028 \% 29$.pdf.

Prasadja, A. (2009). Ayo Bangun! Dengan Bugar Karena Tidur yang Benar (Rahman (ed.); I). Hikmah.

Prasetyo. (2009). Teknik-teknik Tepat Memijat Bayi Sendiri Panduan Lengkap Dan Uraian Kemanfaatannya. Diva Press.

Subakti, Y. \& D. R. A. (2008). Keajaiban Pijat Bayi dan Balita (I). PT WahyuMedia.

Sugiyono. (2016). Metode Penelitian Kuantitatif, Kualitatif dan $R \& D$. Alfabeta.

Sulistyorini, E., \& Cahyaningrum. (2013). Hubungan Pijat Bayi Terhadap Kualitas Tidur Bayi Umur 0-3 Bulan di RB Suko Asih Sukoharjo Tahun 2013. 5, 79-90. https://doi.org/https://doi.org/10.36419/ jkebin.v5i2.94

Suranto, A. (2011). Pijat Anak (A. Indriani (ed.); I). Penebar Plus (Penebar Swadaya Grup). Syaukani, A. (2015). Petunjuk Praktis Pijat, Senam dan Yoga Sehat untuk Bayi. Araska. 